\title{
Effect of Holding Time on Density and Morphological Property of Aluminium Composite Using Recycled Materials by Stir Casting Method
}

\author{
Awwal Hussain Nuhu ${ }^{1,3}$, Suzi Salwah Binti Jikan ${ }^{1 *}$, Saliza Binti Asman'1Nur Azam Bin Badarulzaman² , Dagaci \\ Muhammad Zago ${ }^{1,4}$ \\ ${ }^{1}$ Faculty of Applied Sciences and Technology \\ ${ }^{2}$ Faculty of Mechanical and Manufacturing Engineering \\ Universiti Tun Hussein Onn Malaysia \\ ${ }^{3}$ Department of Chemistry, Faculty of Science Bauchi state University, Gadau - Nigeria \\ ${ }^{4}$ Department of Chemistry, Faculty of Science, Ibrahim Badamasi Babangida University, Lapai, Niger State - Nigeria \\ *Corresponding author E-mail: suzi@uthm.edu.my
}

\begin{abstract}
Aluminium metal matrix composites were fabricated from recycled materials via stir casting method. The composites differed in their holding time (ht) that is 30 minutes, 45 minutes and 60 minutes accordingly. The microstructures of the composites were analysed using optical microscope as well as scanning electron microscope in order to examine their morphological make-up. The average densities of the composites were determined and compared with one another. There is no significant difference between average densities of the fabricated composites. The observations revealed that varying the $h t$ has greater impact the composites' morphology, particularly on those composites which have been fabricated at 60 minutes $h t$.
\end{abstract}

Keywords: Aluminium; Composite; Density; Holding-time; Microstructure; Morphology

\section{Introduction}

The rising demands of materials with enhanced properties and with lesser weight features had increased momentous research activities that lead to further advancement such as Aluminium based composites [1]. Aluminium ( $\mathrm{Al})$ is utilized as diverse materials in numerous fields, for instance in automotive industries, railway and constructions due to its low density, brilliant anticorrosive properties and specific strength. Al is an environmental pleasant material owing to its adeptness to be recycled in addition to its various applications which prove the high demand of $\mathrm{Al}$ production. Solid wastes such as metals and cullet (broken glasses) are neither biodegradable nor water soluble. Recycling of such solid wastes to make new products could lessen the challenge it poses on the natural environment. Therefore, the only option left is to recycle them to get rid them from the environment [2]. Al can be recovered, refined and recycled for further use at an energy cost of just 5 per cent as the one required to produce equal quantity of the metal from its ore [3]. Researchers are experimenting tirelessly, finding ways to strengthen $\mathrm{Al}$ metals and their alloys using ceramic particles in order to advance their qualities making it fit for the desired applications and utilizations in various fields [4]. Many techniques such as powder metallurgy, mechanical milling and various casting procedures, have been used in the formulation of Aluminium metal composites (AMCs) over the past few decades. Amongst all these approaches, melting and casting technique is the most favourable for industries because its relatively cheap and facilitate production [5]. In addition to its low cost, stir casting technique offers a large span of material and processing conditions and also can fabricate composites with up to $30 \%$ volume fraction of reinforcement with improved bonding between metal matrix and the reinforcements due to its stirring action. Considering all these benefits, stir casting technique was choosen particularly for this research for the production of the composites [4]. This paper presents a research on the production Al composites based on AMCs that was entirely sourced from recycled materials which is less expensive engineering materials with lightweight as well as improved efficiency for possible aeronautical and automobile applications. The fabricated composites were assessed in terms of microstructural observations with the aid of Scanning Electron Microscope (SEM) as well as the average densities of the composites.

\section{Materials and Methods}

The $\mathrm{Al}$ composites were fabricated from $\mathrm{Al}$ ingot, copper $(\mathrm{Cu})$ chips and cullet powder (CP) in the proportions of $90 \%, 5 \%$ and $5 \%$ respectively. The matrix element, $\mathrm{Al}$ ingot was placed in a furnace, in a steel crucible, at a temperature of $800{ }^{\circ} \mathrm{C}$ in an electric furnace. After the $\mathrm{Al}$ ingot got melted, preheated $\mathrm{Cu}$ chips were then added and stirred thoroughly. Then, preheated $\mathrm{CP}$ was also added and stirred. The mixture was allowed being heated continuously for a holding time $(h t)$ of 30 minutes. A wetting agent, $\mathrm{Mg}$, was added into the melt and stirred thoroughly by electric hand mixer for $10 \mathrm{sec}$ before it was poured into a cylindrical mould and allowed to cool at room temperature. The same procedure was repeated with $h t$ of 45 minutes and 60 minutes respec- 
tively. Fig. 1 shows the images of the composites' samples after fabrication.
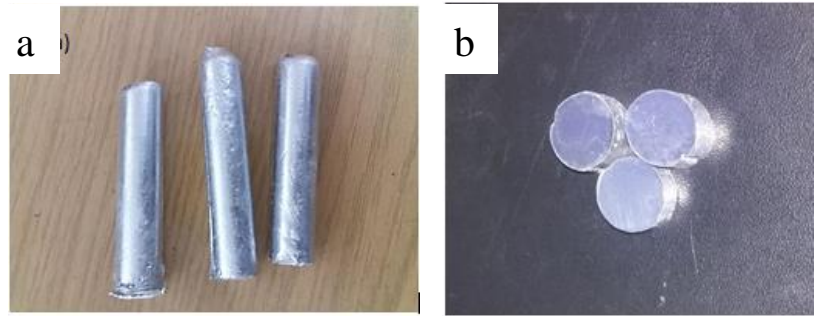

Fig. 1: (a) Samples of the composites after fabrication (b) composites samples after polishing

Specimens were prepared from the fabricated samples for characterizations. The specimens were polished with abrasive papers of grades 200 to 2000 grades, accordingly. The specimens were polished with alumina suspension and etched using Kroll's reagent Scanning electron micrographic (SEM) studies were carried out on the fabricated composites. The densities of the fabricated composites were also determined by measuring the densities of three specimens from each set of samples and taking the average readings. The density measurement was conducted using Mettler Toledo's Density Kits, made in Switzerland (SNR 1129330986) which operates according to Archimedes principles.

\section{Results and Discussions}

\subsection{Optical microscopy analysis}

Micrographs showing the microstructures of the Al-Cu-CP composites fabricated at different $h t$ are presented in Fig. 2. It could be seen that the distribution of reinforcement materials was reasonably homogeneous without noticeable agglomeration. This could be credited to efficient stirring action using electric hand mixer [6] and moreover due to the addition of $\mathrm{Mg}$ as a wetting agent [7]. The distributions of the reinforcements were mostly around the grain boundaries of the matrix in all the three (3) cases. From the micrographs, it is also evident that the dendrite arm spacing was reduced with the increase in the $h t$. The homogeneity has also increased and the reinforcement materials became smaller.
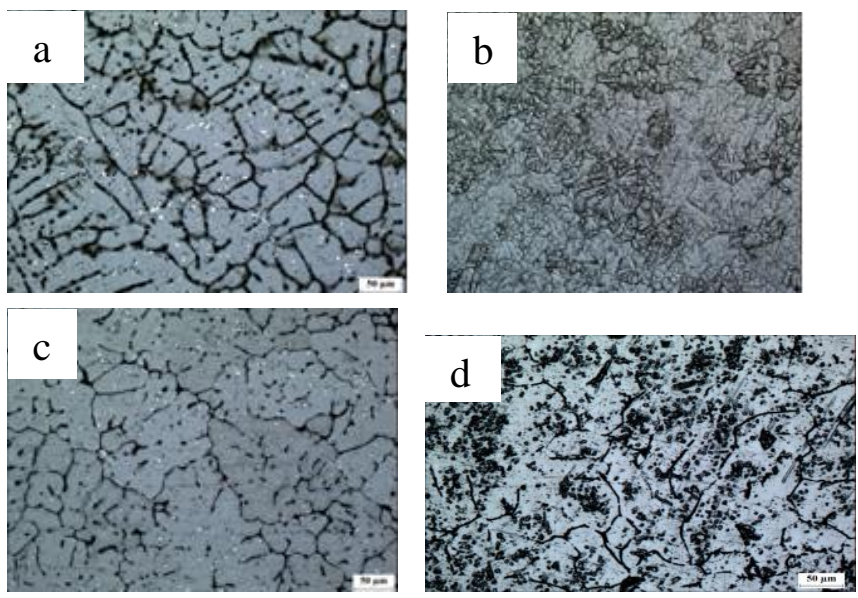

Fig. 2: Micrographs of $\mathrm{Al}-\mathrm{Cu}-\mathrm{CP}$ with $10 \%$ reinforcement fabricated at different $h t$ (a) 30 minutes (b) 45 minutes (c) 60 minutes (d) Al matrix

\subsection{Scanning electron microscopy}

The samples were also analysed using Scanning Electron Microscope (SEM) Hitachi SU1510 model, to understand the interaction between the constituents of the economic composites. It could obviously be observed from the illustrations in Fig. 3, that the uniformity has increased along the trend of the $h t$ and the constituents of the economic composites became more integrated which is desirable to increase the mechanical properties of the products [6]. This makes the composite less brittle and hence its ductility increases with the increase in $h t$ [7]. However, microporosities were also observed between the reinforcement particles and the matrix bulk especially in the composite fabricated at $h t 30$ minutes. The presence of microporosities could be due to the addition of the reinforcements during the time when air was also introduced simultaneously and could be entrapped in the melt when pouring into the moulds [8]. It could also be observed the close similarities of SEM images between the composite fabricated at 60 minutes $h t$ and the control, Al matrix. Thus, signifies highest level of uniformity among all the composites.
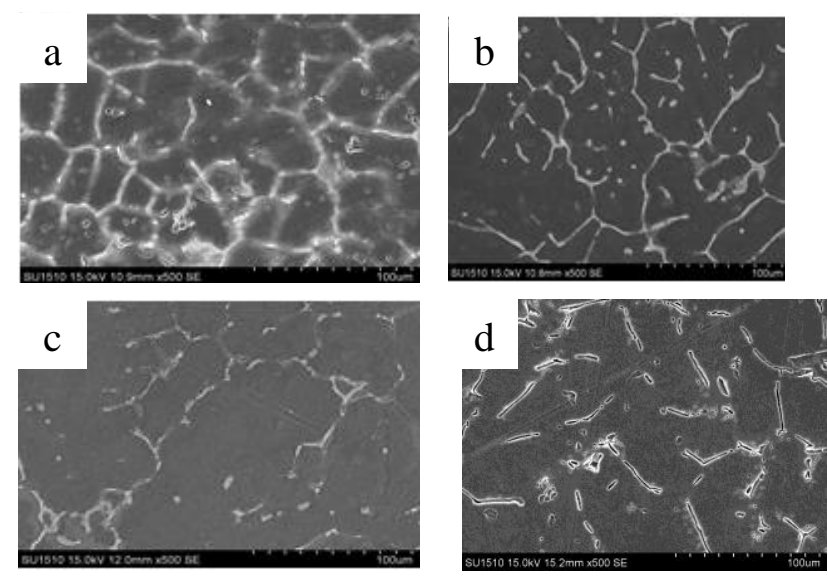

Fig 3: SEM graphs of $\mathrm{Al}-\mathrm{Cu}-\mathrm{CP}$ with $10 \%$ reinforcement fabricated at different $h t$ (a) 30 minutes (b) 45 minutes (c) 60 minutes (d) Al matrix

\subsection{Average densities}

The average densities were measured for each set of the economic composites fabricated and compared with one another to examine any possible variation due to the differences in $h t$ at which the composite were produced as shown in Table 1. The composites fabricated at 60 minutes $h t$ shows the highest density value of $2.772 \mathrm{~g} / \mathrm{cm}^{3}$. This could be attributed to its relatively lesser micropores [6]. Insufficient $h t$ influences the density of the composites by way of creating a huge vacuum between the chips and the matrix as such lowering the density values. Increasing the $h t$ enhances the bonding between the matrix and the reinforcements which would eventually lead to higher and improved density [9]. This could evidently be observed in Fig. 3 shown earlier.

Table 1: Average Densities of $\mathrm{Al}-\mathrm{Cu}-\mathrm{CP}$

\begin{tabular}{|c|c|}
\hline Composites & Average Densities $\left(\mathbf{g} / \mathbf{c m}^{\mathbf{3}}\right)$ \\
\hline $\mathrm{Al}-\mathrm{Cu}-\mathrm{CP}(30)$ & 2.727 \\
\hline $\mathrm{Al}-\mathrm{Cu}-\mathrm{CP}(45)$ & 2.705 \\
\hline $\mathrm{Al}-\mathrm{Cu}-\mathrm{CP}(60)$ & 2.772 \\
\hline
\end{tabular}

\section{Conclusion}

It could be concluded that variation in $h t$ has significant impact on the product composites. Increase in $h t$ yields composites with more homogeneity between the matrix and the reinforcements and properties were more noticeable in those composites with 60 minutes $h t$. Furthermore, the increase in $h t$ improves the uniformity of the composites constituents, reduces the microporosity and also enhances the mechanical properties. However, it was found that variation in $h t$ has no significant effect on the densities of the composites and hence, a plus to the product. 


\section{Acknowledgement}

I wish to acknowledge the contributions of the followings; Materials Science Laboratory of Universiti Tun Hussein Onn Malaysia, my Supervisor Dr Suzi Salwah Binti Jikan, my friends and coresearchers, Muhammad Dagaci Zago and Eng. Abdullahi Tijjani.

\section{References}

[1] Agunsoye JO, Talabi SI, Bello S \& Awe IO (2014), The Effects of Cocos Nucifera (Coconut Shell) on the Mechanical and Tribological Properties of Recycled Waste Aluminium Can Composites. Tribology in Industry 36(2), 155-162.

[2] Al-imari JHG (2014), Fabrication and Mechanical Properties of Economic Composite Materials Using Alumimium Scrap and Wasted Glass. 3rd International Conference on Mechanical, Automobile and Robotics Engineering (ICMAR'2014) Feb. 11-12, 2014 Singapore, (356), 812-824

[3] Nuhu AH, Jikan SS, Asman S, Azam N, Zago DM, \& Bano N (2017), Fabrication and Characterization of Direct Recycled Al-CuCullet Metal Composite. Journal of Science and Technology 9(4), $15-18$.

[4] Sharma P, Sharma S, \& Khanduja DA (2015), Study on Microstructure of Aluminium Matrix Composites. Journal of Asian Ce-
ramic
Societies
(157)
$1-5$ http://doi.org/10.1016/j.jascer.2015.04.001

[5] Anis AL, Ramli R \& Darham W (2016), Microstructure and Mechanical Properties Investigation of in situ TiB2 and ZrB2 Reinforced Al- 4Cu Composites. Materials Science and Engineering 114(2016), 1-5, http://doi.org/10.1088/1757-899X/114/1/012120, (2016).

[6] Srivastava AK, Dixit AR, Tiwari S \& Nagar GB (2016), Investigation of micro-structural and mechanical properties of metal matrix composite A359 / B 4 C through electromagnetic stir casting. Indian Journal of Engineering \& Materials Sciences 23(June), 171-180.

[7] Onat A, Akbulut H \& Yilmaz F (2007), Production and characterisation of silicon carbide particulate reinforced aluminium - copper alloy matrix composites by direct squeeze casting method. Journal of Alloys and Compounds, 436, 375-382, http://doi.org/10.1016/j.jallcom.2006.07.057

[8] Rahman MH \& Al Rashed HMM (2014), Characterization of Silicon Carbide Reinforced Aluminum matrix Composites. Procedia Engineering, 90(2014), 103-109, http://doi.org/10.1016/j.proeng.2014.11.821

[9] Ahmad A, Lajis MA \& Yusuf NK (2017), On the Role of Processing Parameters in Producing Recycled Aluminum AA6061 Based Metal Matrix. Materials, 10(1098), 2-15, http://doi.org/10.3390/ma10091098 